IFN Working Paper No. 1071, 2015

\title{
Stress Reactions Cannot Explain the Gender Gap in Willingness to Compete
}

Thomas Buser, Anna Dreber and Johanna Möllerström 


\title{
Stress reactions cannot explain the gender gap in willingness to compete ${ }^{*}$
}

\author{
Thomas Buser, Anna Dreber and Johanna Mollerstrom
}

\begin{abstract}
Women are often less willing than men to compete, even in tasks where there is no gender gap in performance. Also, many people experience competitive contexts as stressful and previous research has documented that men and women sometimes react differently to acute stressors. We use two laboratory experiments to investigate whether factors related to stress can help explain the gender gap in competitiveness. Experiment 1 studies whether stress responses (measured with salivary cortisol and through self-assessment) to taking part in a mandatory competition predict individual willingness to participate in a voluntary competition. We find that while the mandatory competition does increase stress levels, there is no gender difference in this reaction. Cortisol response does not predict willingness to compete for men but is positively and significantly correlated with choosing to enter the voluntary competition for women. In Experiment 2 we exogenously induce stress using the cold-pressor task. We find no causal effect of stress on competitiveness for the sample as a whole and only tentative evidence of a positive effect for women. In summary, even though there are some gender differences in the relation between stress responses and the decision to enter a competition or not, these cannot explain the general gender gap in willingness to compete that is generally found in the literature and which we replicate.
\end{abstract}

Key words: Gender differences, competitiveness, experiment, cortisol, stress

JEL codes: C90, C91, J16, J71

\footnotetext{
* Buser: School of Economics, University of Amsterdam, and Tinbergen Institute, t.buser@uva.nl. Dreber: Department of Economics, Stockholm School of Economics, anna.dreber@hhs.se. Mollerstrom: Interdisciplinary Center for Economics Science (ICES), Department of Economics, George Mason University, and Research Institute for Industrial Economics, Stockholm, Sweden, jmollers@gmu.com. We are grateful to comments from Magnus Johannesson and participants at seminars at the ESA North America Meetings 2014, University of Amsterdam, University of Toulouse, and the Interdisciplinary Center for Economics Science at George Mason University. We thank the Jan Wallander and Tom Hedelius Foundation (Handelsbankens Forskningsstiftelser), the Knut and Alice Wallenberg Foundation, the Netherlands Organisation for Scientific Research (NWO) and the Speerpunt Behavioural Economics of the University of Amsterdam for generous support. We are very grateful to Rosa Huang, Carolyn Killea, Jeanie Nguyen, Claire Tan and the Harvard Decision Science Laboratory for excellent support in running the experiments.
} 


\section{Introduction}

A vast literature has documented that men with a given ability are more eager than equally able women to enter competitive environments (Bertrand 2010, Niederle and Vesterlund 2010, Niederle 2015). This phenomenon has been documented in the laboratory in contexts where a decision not to compete has negative monetary consequences, in expectation, for people with sufficiently high ability in the relevant task. The gender difference in willingness to compete can partly be traced to differences in confidence and risk aversion, but also when such factors are controlled for, an unexplained gender gap typically remains (Niederle and Vesterlund 2007, Buser et al. 2014). In this paper we replicate the finding of a gender gap in willingness to compete and relate it to two other facts: first, competitions are often perceived as stressful, and second, research has documented that men and women sometimes react differently to acute stress (e.g. Taylor et al. 2000). Using two laboratory experiments, we first examine if participating in a competition causes stress and whether differences in such stress reactions can explain individual and gender differences in willingness to compete. We thereafter investigate if there is a causal effect of stress on willingness to compete.

That there is substantial individual variation in willingness to compete, and that women tend to be overrepresented among those who opt out of competitive environments, was first documented in the seminal work of Niederle and Vesterlund (2007). We follow their design and have participants perform a simple arithmetic task in three separate five-minute rounds. In the two initial rounds, participants are exposed to first a piece-rate and then a competitive payment scheme. Ahead of round 3, they get to choose which of the two payment schemes to apply to that round. The decision about whether or not to compete in round 3 is a standard measure of willingness to compete.

The fact that women to a significantly higher extent than men opt out of this type of competitions has been documented in many (but not all) societies and across age groups (e.g., Gneezy et al. 2009, Cárdenas et al. 2012, Flory et al. 2012, Mayr et al. 2012, Andersen et al. 2013, Almås et al. forthcoming, Apicella and Dreber forthcoming, Sutter and Glätzle-Rützler forthcoming), and this tendency appears to be particularly strong for math-related tasks (Günther et al. 2009, Grosse and Reiner 2010, Dreber et al. 2014). Moreover, willingness to compete in the laboratory is correlated with behavior with substantial economic consequences outside of the abstract experimental setting: Zhang (2012) shows that individuals who are more willing to compete in the laboratory are more likely to take a competitive high school entrance exam in China; Buser et al. (2014) find that individuals with a stronger willingness 
to compete choose more math oriented and prestigious high school tracks in the Netherlands; Reuben et al. (2013), in the US, find that college students with a higher willingness to compete expect to have higher future earnings; and Oppedal Berge et al. (fortcoming) find that willingness to compete predicts the investment decisions of Tanzanian entrepreneurs. Hence, the gender gap in willingness to compete is likely a partial explanation for gender differences in career choices (see also Bertrand 2010 and Flory et al. 2010).

In order to address the gender gap in labor market outcomes it is important to understand the origins and determinants of the gender difference in willingness to compete. Previous research (which has mostly, but not exclusively, focused on risk preferences) has documented that men and women sometimes react differently to acute stressors (e.g. Taylor et al. 2000, Lighthall et al. 2009, van den Bos et al. 2009, Angelucci and Córdova 2014, Kandasamy et al. 2014). ${ }^{1}$ Based on this literature, we investigate if factors related to stress can explain the gender gap in willingness to compete. Stress responses are typically triggered in situations that are novel, unpredictable, threatening or uncontrollable and it has been shown that situations where one's performance is evaluated or compared to others' are particularly stressing (Dickerson and Kemeny 2004, von Dawans et al. 2011). It hence seems likely that the mandatory competition in round 2 of our experiment could be perceived as stressful.

Our primary measure of acute stress comes from cortisol levels in saliva. Cortisol is considered the human body's stress hormone; it reacts to both physical and psychological stressors through the autonomic nervous system and the hypothalamic-pituitary-adrenal axis (Dickerson and Kemeny 2004) and it can be easily and accurately measured in saliva (e.g., Vining et al. 1983, Kirschbaum and Hellhammer 1989). We also measure stress through selfassessments.

Our paper reports on the results of two experiments. Experiment 1 asks if an individual's stress response to taking part in the mandatory competition in round 2 of the experiment predict his or her willingness to enter the voluntary competition in round 3. Experiment 2 exogenously induces physiological stress using the cold-pressor task and investigate if there is a causal effect of acute stress on willingness to compete. We focus on the importance of stress in understanding the gender gap in willingness to compete and note that there are two ways in

\footnotetext{
${ }^{1}$ There is also a literature investigating the links between stress and preferences (again mostly risk-taking) without investigating potential gender differences, and with mixed results. See, e.g., Coates and Herbert (2008), Porcelli and Delgado (2009), von Dawans et al. (2012), Chumbley et al. (2014) and Schipper (2014). Moreover, there is a vast literature correlating stress indicators such as cortisol levels with other types of risk taking than economic risk taking; see for example Mehta et al. (in press).
} 
which stress reactions could explain gender differences in competitiveness. First, if the effect of stress on willingness to compete is the same for men and women, a gender difference in the stress reaction to competition could explain gender differences in willingness to compete. Second, there could be a gender difference in the effect of stress on willingness to compete.

In addition to shedding light on the origins of the gender gap in willingness to compete, our study also helps enhance our understanding of the economic determinants and consequences of stress through measuring stress reactions related to different payment schemes.

We replicate the common finding that women are less willing than men to compete. We also find that the mandatory competition in round 2 does increase stress levels. We find no gender difference in stress reactions to the mandatory competition. This means that cortisol levels of men and women reacting differently to competitive pressure is not an explanation for the gender gap in willingness to compete. However, we find that for women, but not for men, stress reactions to competition are positively related to willingness to compete: while there is a large and statistically significant gender gap in choosing competition for participants with below-average cortisol reactions, the gender difference is small and insignificant for those with above-average reactions.

Our randomized stress treatment, the cold-pressor task, has a significant positive effect on cortisol levels. However, this increase in cortisol does not lead to a significant change in willingness to compete for the sample as a whole. We do, however, find some tentative evidence of a positive causal effect on women's willingness to compete, indicating that the predictive power of cortisol reactions for women could be due to a causal effect of stress reactions on willingness to compete.

In Experiment 1, we also have data on electrodermal activity measured through skin conductance. This is a proxy for both positive and negative psychological and physiological arousal. We test whether skin conductance response or self-reported excitement from participating in the mandatory competition can predict willingness to compete and find evidence of neither. However, we find that the skin conductance response to performing the task under a piece rate scheme positively predicts competitiveness. Our results hence suggest that those who find performing in the task more exciting are also more likely to compete in that task.

Given that we document both a gender difference in willingness to compete and a stress reaction following the competition, our data are uniquely suited to analyze the role of stress in 
explaining the gender difference in competitive attitudes. We conclude that even though we find some evidence of women and men displaying different relations between stress reactions and the decision about whether or not to compete, this does not provide an explanation for why women in general are less willing than men to compete.

To our knowledge, our paper is the first to both explore the correlation between stress levels and willingness to compete and provide a test of the causal impact of acute stress on competitiveness. We are also the first to provide a detailed investigation into the potential for stress to explain the gender gap in willingness to compete. We know of only two other studies that looks at the correlation between stress and competitiveness. In a sample of male participants (not investigating any potential gender difference), Apicella et al. (2011) study willingness to compete in a maze task where participants have not performed any previous rounds of the task. Simply correlating baseline cortisol levels with competitiveness, they show that there is no significant relationship. Using the Niederle and Vesterlund (2007) competitiveness design, Buckert et al. (2015) correlate willingness to compete with heart rate variability and blood pressure, both which can be proxies of stress levels but also for other forms of arousal, as well as cortisol and testosterone in a mixed gender sample. They find no evidence of cortisol reacting to the forced competition or predicting willingness to compete.

Two other studies are more loosely related to our paper: Similarly to Buckert et al. (2015), Halko et al. (2014) also use the Niederle and Vesterlund (2007) setup and explore to what extent heart rate variability correlates with gender differences in willingness to compete. While Buckert et al. (2015) find some evidence suggesting that that heart rates increase for those forced to compete independently of gender, Halko et al. find men's heart rate variability reacts more when competing than women's. However, neither study finds that heart rate variability can explain the gender gap in competitiveness. In a different type of task, Goette et al. (2015) find that randomly stressing participants with a social stressor in a competitive context makes low-anxiety individuals overconfident whereas high-anxiety individuals become underconfident. ${ }^{2}$

The remainder of the paper is organized as follows: Section 2 describes the design of the two experiments. In section 3 we present our results and Section 4 concludes.

\footnotetext{
${ }^{2}$ The competitive context involves participants making a decision based on self-confidence about their cognitive ability.
} 


\section{The two experiments}

We conduct two laboratory experiments to examine both the correlation between a person's stress reaction to a mandatory competition and her willingness to enter a voluntary competition (Experiment 1), as well as investigate whether there is a causal effect of stress on willingness to compete (Experiment 2). ${ }^{3}$

\subsection{Experiment 1: Design}

We closely follow the design of Niederle and Vesterlund (2007) and have participants perform a simple arithmetic task where they add sets of five two-digit numbers. They perform the task in three rounds, for 5 minutes per round. In round 1, participants perform the task and are paid according to a piece-rate payment scheme where they get $\$ 1$ per correctly solved problem. In round 2, participants are placed in groups with three randomly chosen other participants. They perform the task again and the participant with the highest score in each group is in this round paid $\$ 4$ per correctly solved problem while the others receive nothing. In round 3, participants choose between being paid according to a piece-rate payment scheme, as in round 1 , or according to a competitive payment scheme, as in round 2. They thereafter perform the task again. If a participant chooses to compete, she will compete against the second round performance of the same three participants (this guarantees that the choice has no externalities on the payoffs of others). Participants are not getting any feedback on their relative performance during the experiment. At the end they are paid in private for one randomly chosen round.

We measure cortisol levels from saliva at three different points during in the experiments. Saliva was sampled using oral swabs, samples were frozen immediately after collection and subsequently sent to the company Salimetrics where each sample was analyzed in duplicate. Cortisol levels are known to rise significantly within minutes of the onset of a stressor, and stay elevated for at least 20-40 minutes after the end of the stressful task or event (Dickerson and Kemeny 2004). The first saliva sample was collected at the start of the study (before any other instructions were given). The second saliva sample was collected 10 minutes after the end of round 1 and the third 10 minutes after the end of round 2. We implemented the 10minute delays since there is a delay between the increase of cortisol and the possibility to observe it in saliva. Thereby we get correct measures of the cortisol response from the piece

\footnotetext{
${ }^{3}$ All experimental instructions and questionnaires are available in the Online Appendix.
} 
rate payment scheme in round 1 and the mandatory competition in round 2 from the second and third saliva sample respectively.

We also measure self-reported emotions (stress, excitement, happiness and anger) before the start of the study, and immediately after rounds 1 and 2. Immediately after round 3 we also ask participants to guess their rank in rounds 1 and 2 compared to the other three participants in their randomly assigned group. Participants receive $\$ 2$ for each correct guess.

Skin conductance is regarded as a measure of electrodermal activity which is a proxy of psychological and physiological arousal (Mendes 2009). We measure it throughout Experiment 1 in order to be able to assess other types of arousal in addition to stress. We applied two electrodes on each participant's non-dominant hand before the start of the experiment and used MindWare ${ }^{\mathrm{TM}}$ to measure the electrical conductance of the skin, which varies with its moisture level.

At the end of the study participants answered a short questionnaire that among other things collected information on gender, age and the intake of hormonal medication, such as oral contraceptives. The questionnaire also elicited risk attitudes through a simple, nonincentivized question: "How do you see yourself: Are you generally a person who is fully prepared to take risks or do you try to avoid taking risks?”. The answer is on a scale from 0 (“unwilling to take risks") to 10 ("fully prepared to take risks”). This question has been found to predict both incentivized choices in a lottery task and risky behaviors in different contexts in representative samples (Dohmen et al. 2011).

\subsection{Experiment 2: Design}

The main difference between Experiment 1 and Experiment 2 is that in the latter we employ the cold-pressor task to exogenously increase cortisol levels in a random sample of participants. In the cold-pressor task participants are asked to immerse their dominant hand into a bucket of ice-cold ( 0 degrees Celsius) water for 90 seconds. The treatment is widely used as a physiological stressor as it produces a sharp increase in participants' cortisol levels (see, e.g., Errico et al. 1993, Porcelli and Delagado, 2009 and Delaney et al., 2014).

The cold-pressor task was administered to half of the participants immediately after round 2. Randomization was done at the individual level and 51 participants received the cold-pressor treatment. The remaining 52 participants had their dominant hand in a bucket of pleasantly warm (30-35 degrees Celsius) water for 90 seconds. 
As in Experiment 1, we collect saliva three times: at the beginning of the experiment, 10 minutes after round 1, and 15 minutes after round 2. ${ }^{4}$ The questionnaire for Experiment 2 was different from the one in Experiment 1 only in that it asked participants to report how hard they found it to keep the hand in the water, and to estimate how long they had the hand in the water (if they did not manage to do it for 90 seconds).

\subsection{Implementation}

The experiments were conducted at the Harvard Decision Sciences Laboratory in Cambridge, MA. Experiment 1 was conducted in March and April 2014 and Experiment 2 in September and October 2014. Participants were recruited through the laboratory's subject pool and mainly consisted of students at Harvard University. The experiments were programmed in zTree (Fischbacher 2007) and approved by the Harvard University Committee for the Use of Human Subjects.

104 people participated in Experiment 1 (50 men and 54 women) and 103 people participated in Experiment 2 (46 men, 57 women). ${ }^{5}$ Sessions in Experiment 1 lasted on average 65 minutes whereas sessions in Experiment 2 were on average 10 minutes longer. In both Experiment 1 and 2 participants earned on average \$25.5.

\subsection{Standardization of variables}

Levels of salivary cortisol and skin conductance are not suitable for our analysis given that they vary strongly between individuals in ways that are unrelated to the experiment (cortisol levels in saliva depend for example on how much an individual salivates, while skin conductance levels depend on a person's natural tendency to sweat).

We therefore use individual baseline levels to standardize the measurements taken during the experiment. That is, we divide the second and third measures of cortisol and mean skin conductance levels during the task performances by the measurements taken at the start of the experiment. Thus for skin conductance we focus on skin conductance response rather than

\footnotetext{
${ }^{4}$ The reason that we asked participants to wait for 15 minutes after the cold-pressor task was that we wanted the total time between the onset of the (potentially) stressful task (i.e. the math task in Experiment 1 and the coldpressor task in Experiment 2) to be as similar as possible.

${ }^{5}$ The reason that the sample size is not divisible by 4 is that even though participants were randomly grouped with three other participants, these participants were not necessarily grouped with the same other participants.
} 
skin conductance levels (see Mendes 2009 for a discussion of the difference between these measures).

\section{Results}

\subsection{Is there a gender difference in the willingness to compete?}

In Table 1 we show summary statistics for Experiment 1 . Women are significantly less likely to choose to compete in round 3 than men ( $\mathrm{p}=0.02$; Fisher's exact test). Even though there are no significant gender differences in performance (round one: $\mathrm{p}=0.24$, round two: $\mathrm{p}=0.62$; rank-sum tests), only 28 percent of the women choose to compete while the corresponding number for men is 52 percent. In Table 2 we show the results for the gender gap in the willingness to compete using OLS regressions adding controls for performance (column 2), performance beliefs (column 3), and risk attitudes (column 4). In columns 1-3 women are significantly less willing to compete than men, however this gender gap is no longer significant once we control for risk attitudes.

\subsection{Does competing cause stress?}

Figure 1 shows standardized cortisol levels and self-rated stress levels after the piece-rate round (round 1) and after the mandatory competition round (round 2) in Experiment 1. We find that competition causes stress. Cortisol levels after the piece-rate are on average not significantly different from baseline levels (an increase of 3.8 percent, $\mathrm{p}=0.29$; paired t-test) but levels after the competition are significantly higher compared to baseline (an increase of 13.3 percent, $\mathrm{p}=0.03$ ) and compared to after the piece-rate round (an increase of 11.6 percent, $\mathrm{p}=0.02$ ). In a similar vein, we find that self-rated stress levels after the piece-rate round are not higher than baseline levels $(\mathrm{p}=1.00)$ while competition levels are 10.6 percent higher than baseline $(\mathrm{p}=0.02)$ and piece-rate levels $(\mathrm{p}<0.01){ }^{6}$

We also analyze skin conductance response and self-reported excitement as two proxies of arousal. Baseline skin conductance levels are defined as the average level of skin conductance

\footnotetext{
${ }^{6}$ The order of the piece-rate and competition performances was not randomized but the fact that neither cortisol nor self-assessed stress increased during the first round makes it unlikely that our results are reflecting a mere order effect.
} 
during the period between reading the welcome screen and reading the instructions for the first round (this is also the period during which the first saliva sample was collected). The piece-rate and competition response of skin conductance are defined as average skin conductance during the five-minute piece-rate and competition performances (rounds one and two respectively). These are standardized by baseline levels. In Figure 2, our results suggest that performing the task itself causes arousal. Compared to baseline, piece-rate skin conductance is 26 percent $(\mathrm{p}<0.01)$ higher and self-rated excitement similarly increases by 15 percent compared to the baseline $(\mathrm{p}<0.01)$. Skin conductance levels increase 8 percent during the competition $(\mathrm{p}<0.01)$ compared to piece-rate levels and 35 percent compared to baseline $(\mathrm{p}<0.01)$. Self-rated excitement increases by 4 percent during the competition compared to piece-rate levels $(\mathrm{p}=0.23)$ and 19 percent compared to baseline $(\mathrm{p}<0.01)$.

\subsection{Can differential stress reactions explain the gender gap in willingness to compete?}

After having documented that there is a gender difference in willingness to compete and that the mandatory competition increases stress for the average participant, we now move on to investigating if stress-related factors can help explain the gender difference in competitiveness.

We find no gender differences in stress reactions depending on the payment scheme. In Figure 3, we show that neither the cortisol response nor the self-assessed stress response to the competition in round 2 differ between men and women (cortisol: $\mathrm{p}=0.82$, self-rated stress: $\mathrm{p}=0.33$; t-tests). There is thus no evidence that men and women have different stress reactions to being forced to compete in round 2.

We next explore whether stress reactions to competing in round 2 predict willingness to compete in round 3. Figure 4 illustrates that neither the change in standardized cortisol nor the change in self-rated stress in response to competing differ much between those participants who chose the piece-rate and those who chose the competition in round 3.

These results are confirmed by the regressions in Table 3. Neither the cortisol reaction to competition (column 4) nor the reaction of self-rated stress (column 5) predict the choice of payment scheme in round 3. Apart from being statistically insignificant, the magnitudes of the coefficients are small. As an illustration, an increase in cortisol levels equal to the average increase would lead to an increase in the likelihood of choosing the competition in round 3 of around 1 percentage point. Furthermore, there is no change in the gender gap in competition 
entry compared to column 1. From Figure 4, we can see that those who choose to compete in round 3 experience a somewhat higher increase in cortisol and self-rated stress during the piece-rate performance. Columns 2 and 3 of Table 3 show that this difference is not significant. That is, how stressed a participant gets by performing the task under piece-rate incentives does not predict choosing competition either.

Figure 5 looks at gender differences in arousal and excitement. While there is no gender difference in the reaction of skin conductance to competition $(\mathrm{p}=0.30)$, women experience a stronger increase in self-rated excitement $(\mathrm{p}<0.01)$. In Figure 6 and Table 4 we explore whether changes in arousal and excitement predict willingness to compete in round 3 and whether they can explain the gender gap in competitiveness. As Figure 6 shows, those participants who choose to compete in round 3 show a stronger skin conductance response both when comparing the piece-rate performance to baseline $(p=0.04)$ and when comparing the competition to the piece rate $(\mathrm{p}=0.06)$. Those who choose to compete also show a stronger reaction in self-rated excitement during the piece-rate performance $(\mathrm{p}<0.01)$ but not during competition compared to piece rate $(\mathrm{p}=0.15)$.

This is further explored in Table 4, where we regress a dummy for choosing the competition in round 3 on a female dummy and on skin conductance response and self-rated excitement. Columns 1 to 4 confirm that participants who experienced an increase in arousal in response to performing in the task (column 2) and those who experience an increase in arousal in response to competition (column 4) are more likely to choose to compete. When all measures of arousal (piece-rate and competition skin conductance responses and self-rated excitement) are included in column 6, although no individual measure is significant, they jointly significantly predict willingness to compete ( $\mathrm{p}=0.028$; Wald test). Individual differences in arousal cannot explain the gender gap in competitiveness: the gender coefficient actually increases between column 1 and column 6 .

In sum, while our results suggest that stress levels react to the payment scheme, stress reactions do not predict willingness to compete. Furthermore, gender differences in stress reactions to competition are not an explanation for the gender gap in competitiveness. Our results also suggest that arousal or excitement react to the payment scheme and that this can predict willingness to compete, yet again these variables do not seem to affect the gender gap in willingness to compete. 
3.4 Is there a gender difference in the correlation between stress and willingness to compete?

We have shown that there is no gender difference in the stress reaction to competition and that, overall, stress reactions do not significantly predict competitive choices. Given that some studies have found gender differences in the behavioral consequences of stress responses, we now investigate whether our null result hides a differential response of men and women to the stress reaction caused by the competition.

In Table 5, we explore this using different methods. In column 1, we regress the choice of compensation scheme in round 3 on standardized cortisol levels after the piece-rate performance in round 1 , a female dummy and the interaction of the two. In column 2 , we do the same for cortisol levels after the competition in round 2. In columns 3 and 4, we regress the competition dummy on standardized cortisol levels for men and women separately. In columns 5 and 6, we split the sample into those with below-average and above-average cortisol levels after the piece-rate performance in round 1 and in columns 7 and 8 we split the sample into those with below-average and above-average cortisol levels after the competition in round 2.

The gender-interaction regressions in columns 1 and 2 suggest that there might indeed be a gender difference in the correlation between stress reactions and the willingness to compete. While the coefficients on cortisol after piece-rate (column 1) and competition (column 2) are small and negative for males, the coefficients on the gender interactions are large and positive. In the case of cortisol after piece-rate, the interaction is significant at the 10 percentlevel. We can see from column 3 that standardized cortisol levels after competition do not predict competition entry for men. This looks different for women (column 4). Women who show a stronger cortisol increase compared to baseline are significantly more likely to choose competition $(\mathrm{p}<0.05)$. The regressions in columns 5 and 6 confirm this pattern and demonstrate the relationship between the gender gap in willingness to compete and stress reactions. While there is a strong and significant gender gap in the likelihood to choose competition for those with a below average cortisol levels after competition (column 5), the gender difference in close to zero for those with above-average levels (column 6).

In summary we find that for men the willingness to enter a competition does not depend on stress reactions: those who show a strong cortisol increase when performing the task are just as likely to compete as those who show a weak response. For women on the other hand, those who experience a strong cortisol response are more likely to compete and this effect is so 
strong that there is no gender gap in competitiveness for participants with an above-average standardized cortisol level after competition.

\subsection{Is there a causal effect of stress on the willingness to compete?}

We now move on to investigate whether there is a causal effect of stress on the willingness to compete. This will also help us disentangle possible explanations for the gender difference in the predictive power of cortisol responses: is it simply the case that women who show a stronger cortisol response have a preference for competition, or does the stronger cortisol response actually make them compete more?

In Table 6 we show summary statistics for Experiment 2. As in Experiment 1, women are significantly less willing to compete than men $(p<0.01)$. Only 30 percent of the women choose to compete in round 3 while almost twice as many men (59 percent) choose to do so. Similarly to our results in Experiment 1, this gender gap shows up even though men and women perform equally well in the piece-rate (round 1) and the competition (round 2) (round $1: \mathrm{p}=0.76$, round $2: \mathrm{p}=0.31$ ).

Given that our third cortisol measurement was taken after the cold-pressor task in Experiment 2 (to check that the manipulation worked) we cannot conduct the same cortisol analysis as for Experiment 1. However, we measured self-rated stress and excitement and these measurements were taken before the stress treatment. As Figure 7 shows, we replicate the effects of competition found in the first experiment: self-rated stress increases by 11.4 percent in response to competing $(\mathrm{p}<0.01)$ while there is no change in excitement $(\mathrm{p}=0.96)$. As in Experiment 1, excitement increases in response to the piece-rate performance $(p<0.01)$. Contrary to Experiment 1, there is now also an increase in self-rated stress in response to the piece-rate performance $(\mathrm{p}=0.06)$.

Turning to the stress treatment, Figure 8 shows that it was successful in that it increased cortisol levels by 44 percent $(p<0.01)$ relative to the control group. In Table 7 , we estimate the impact of the stress treatment on the willingness to compete. Columns 1 and 2 confirm that conditional on performance and guessed performance in the first two rounds, we find a similar gender difference in the likelihood of choosing competition as in Experiment 1. Columns 3 and 4 show that this time the gender coefficient does not change much when we control for confidence and self-rated risk attitudes. In Columns 5 and 6, we add a dummy for 
the cold-pressor treatment. Despite the large impact of the treatment on cortisol levels, there is no significant impact on the likelihood to compete for the sample as a whole. ${ }^{7}$

Following our findings of a differential impact of cortisol levels by gender in Experiment 1, we now move to analyze gender differences in the impact of the stress treatment. In column 1 of Table 8, we interact the treatment dummy with gender. While the coefficient on the interaction is large and positive (indicating that the effect of the stress treatment is larger and positive for women) it is not statistically significant. To check whether the stress treatment worked, we asked the following question in the post-experimental questionnaire: "Did you find it hard or easy to keep the hand in the water for 90 seconds?” (on a scale from 1="very hard" to $10=$ "very easy"). In column 2, we restrict the treatment group to those who gave an answer of 3 or lower. The coefficient on the gender interaction is large and statistically significant. ${ }^{8}$ In column 3 , we use standardized cortisol levels at the third measurement (that is, after the stress treatment) instead of a treatment dummy and the result is the same: the impact of cortisol on competition entry is significantly stronger and positive for women compared to men.

In columns 4 and 5 we run separate regressions for men and women. While the effect of the stress treatment on the likelihood to compete is -9.5 percentage points for men, it is larger and positive for women at 16.5 percentage points. But again, neither of these coefficients are significant. In columns 6 and 7 we run separate regressions for the treatment and control groups. While we find a large and statistically significant gender difference in the control group, the gender gap is much smaller and not statistically significant in the treatment group.

Together, the results of the two experiments indicate that the willingness to compete of women, but not men, is partially explained by cortisol changes. The results of the second experiment tentatively suggest that this might be due to a causal effect (stronger cortisol reactions leading to a higher willingness to enter competitions for women). But more research with larger samples is needed to draw firm conclusions (for example, to detect the difference in choosing competition between treatment and control for the female subsample in column 5 of Table 8 with $80 \%$ power, one would need a sample of 240 women).

\footnotetext{
${ }^{7}$ Kirschbaum et al. (1994) find that oral contraceptives might dampen the cortisol response to stress and the results of Buser (2012) raise the possibility of a direct impact of oral contraceptives on the willingness to compete. When we control for contraceptive intake in the regressions in Table 7 as a robustness check, none of the results change. Controlling for the intake of psychoactive medicine does not change the results either.

${ }^{8}$ This result is robust to using a cutoff of 1,2 or 4 instead of 3 .
} 


\subsection{Is there an effect of stress on performance?}

Some studies find that (acute) stress is good for productivity and performance (e.g., Kavanagh 2005). We will therefore briefly discuss whether, in our experiments, stress reactions and randomly induced stress have an impact on performance. Table 9 shows OLS regressions of scores in rounds 2 and 3 on stress indicators controlling for scores in round 1 . The coefficients on the stress indicators are therefore conditional on round 1 performance; that is, they show whether stress correlates with or causes an increase in performance. In columns 1 and 2, we regress scores in round 2 on standardized cortisol after the piece-rate performance and after the competition. In both cases, the coefficient is statistically insignificant, that is we find no evidence for an impact of stress reactions on performance. In columns 3 and 4, we do the same for standardized skin conductance during the piece-rate and competition rounds, finding no evidence of an impact of arousal on performance. In columns 5 to 7 , we move to the second experiment to determine whether randomly induced cortisol levels have an impact on performance in round 3. In column 5, we show that the random stress treatment have no impact on scores in round 3 conditional on initial scores and the choice of payment scheme. In the last two columns we show that standardized cortisol levels after the piece-rate performance (before the random stress treatment) and after competition (after the random stress treatment) do not predict round 3 scores either.

\section{Discussion}

In order to design and implement adequate policies that address gender differences in labor market outcomes, it is important to know the mechanisms underlying the gender gap in willingness to compete. Given that men and women have been found to react differently to stress in other tasks, and that many individuals perceive competitions as stressful, we investigate whether individual differences in acute stress reactions to a mandatory competition can explain the gender difference in willingness to compete.

We find a gender gap in willingness to compete and we document that performing under competitive incentives is stressful for the average individual. We find no impact of stress on willingness to compete for men. Men who show a stronger stress reaction to performing the task either under the piece-rate or the competitive incentive scheme are neither more nor less likely to compete and our randomized exogenous stress treatment has no impact on men's willingness to compete. However, stress reactions to performing in the task positively predict 
willingness to compete for women. This correlation is strong enough that the gender gap in competitiveness disappears for those subjects with a larger than average stress reaction to competition. We investigate if this is due to selection (women who show a stronger cortisol reaction to performing in a competition like competition more) or to a causal effect of stress on the willingness to compete. We find tentative evidence that the randomized exogenous stress treatment has a stronger effect on women's willingness to compete, hinting at a causal relationship, but more research is needed.

To what extent do our results indicate that stress reactions can "explain" the gender gap in competitiveness? Differential stress reactions to being in a competitive situation clearly cannot explain why women are less willing to compete than men: women and men get equally stressed by competing. Controlling for cortisol reactions (Experiment 1) or the randomized exogenous stress treatment (Experiment 2) also does not alter the gender gap at all. We do find that for women, willingness to compete is more sensitive to cortisol changes than for men. However, if anything, this leads to a smaller gender gap for those who get stressed by the competition and we therefore conclude that even though there are some gender differences in the relation between stress reactions to the competition in round 2 and willingness to compete in round 3, these cannot explain why women in general more often opt out of this type of competitive environments.

Cortisol prepares the individual for an oncoming confrontation or fight and it therefore makes sense that those who experience a stronger cortisol reaction are more willing to face a competition. The question is why we see evidence of this only for women. Potentially, we do not find this effect for men because of their already very high willingness to compete (many men enter the competition in round 3 with very low chances to win). It is hence possible that whereas men compete no matter what in this type of setting, for women stress reactions could help to overcome an inclination to avoid competitive situations.

While acute stress reactions can be beneficial, chronic stress is associated with a long list of adverse health outcomes. If our result of a competitive payment scheme leading to increased stress for the average individual extrapolates to the workplace, it could mean that competitive remuneration schemes and promotion mechanisms have negative effects on the long-term 
health of employees. This, in turn, opens up an interesting avenue for research into the health consequences of different payment schemes and other workplace practices. ${ }^{9}$

\footnotetext{
${ }^{9}$ One study which directly focuses on this topic is Falk et al (2011) who find a link between the perceived unfairness of the remuneration for a tedious task and heart rate variability, which predicts heart diseases in the long run.
} 


\section{References}

Almås, I., A.W. Cappelen, K.G. Salvanes, E. Sørensen and B. Tungodden, forthcoming. Willingness to compete: family matters. Management Science.

Andersen, S., S. Ertac, U. Gneezy, J. List and S.F. Maximiano, 2013. Competitiveness and socialization at a young age: Evidence from a matrilineal and a patriarchal society. Review of Economics and Statistics, 95(4), 1438-1443.

Angelucci, M. and K. Córdova, 2014. Productivity and choice under stress: Are men and women different? Working paper.

Apicella, C.L. and A. Dreber, forthcoming. Sex differences in competitiveness: Huntergatherer women and girls compete less in gender-neutral and male-centric tasks. Adaptive Human Behavior and Physiology.

Apicella, C.L. A. Dreber, P. Gray, M. Hoffman, A.C. Little and B.C. Campbell, 2011. Androgens and competitiveness in men. Journal of Neuroscience, Psychology, and Economics, 4, 54-62.

Bertrand, M., 2010. New perspectives on gender. In Handbook of Labor Economics, 15431590.

Buckert, M., C. Schwieren, B.M. Kudielka and C.J. Fiebach, 2015. How stressful are economic competitions in the lab? An investigation with physiological measures. Working paper.

Buser, T., 2012.The impact of the menstrual cycle and hormonal contraceptives on competitiveness. Journal of Economic Behavior \& Organization. 83(1), 1-10.

Buser, T., M. Niederle and H. Oosterbeck, 2014. Gender, competitiveness and career choices. Quarterly Journal of Economics, 129(3), 1409-1447.

Cárdenas, J.-C., A. Dreber, E. von Essen and E. Ranehill, 2012. Gender differences in competitiveness and risk taking: comparing children in Colombia and Sweden. Journal of Economic Behavior \& Organization, 83(1), 11-23.

Chumbley, J.R., I. Krajbich, J.B. Engelmann, E. Russell, S. Van Uum, G. Koren and E. Fehr, 2014. Endogenous cortisol predicts decreased loss aversion in young men. Psychological Science, 25(11), 2102-2105. 
Coates, J.M. and J. Herbert, 2008. Endogenous steroids and financial risk taking on a London trading floor. Proceedings of the National Academy of Sciences, 105, 6167-6172.

Croson, R., and U. Gneezy, 2009. Gender differences in preferences. Journal of Economic Literature, 47(2), 1-27.

Delaney, L., G. Fink and C. Harmon, 2014. Effects of stress on economic decision-making: Evidence from laboratory experiments. Working paper.

Dickerson, S.S. and M.E. Kemeny, 2004. Acute stressors and cortisol responses: a theoretical integration and synthesis of laboratory research. Psychological Bulletin, 130(3), 355-391.

Dohmen, T., A. Falk, D. Huffman, U. Sunde, J. Schupp and G.G. Wagner, 2011. Individual risk attitudes: Measurement, determinants and behavioral consequences. Journal of the European Economic Association, 9(3), 522-550.

Dreber, A., E. von Essen and E. Ranehill, 2014. Gender and competition in adolescence: Tasks matter. Experimental Economics, 17(1), 154-172.

Falk, A., I. Menrath, P. Verde and J. Siegrist, 2011. Cardiovascular consequences of unfair pay. Working paper.

Fischbacher, U., 2007. z-Tree: Zurich toolbox for ready-made economic experiments. Experimental Economics, 10, 171-178.

Flory, J., U. Gneezy, K.L. Leonard and J.A. List, 2012. Sex, competitiveness, and investment in offspring: On the origin of preferences. Working paper.

Flory, J., A. Leibbrandt and J.A. List, 2010. Do competitive work places deter female workers? A largescale natural field experiment on gender differences in job-entry decisions. Working paper.

Gneezy, U., N. Niederle and A. Rustichini, 2003. Performance in competitive environments: gender differences. Quarterly Journal of Economics, 118(3), 1049-1074.

Gneezy, U., K.L. Leonard and J.A. List, 2009. Gender differences in competition: Evidence from a matrilineal and a patriarchal society. Econometrica, 77(5), 1637-1664.

Goette, L., S. Bendahan, J. Thoresen, F. Hollis and C. Sandi, 2015. Stress pulls us apart: Anxiety leads to differences in competitive confidence under stress. Psychoneuroendocrinology, 54, 115-123. 
Grosse, N.D. and G. Reiner, 2010. Explaining gender differences in competitiveness: Gendertask stereotypes. Working paper.

Günther, C., N. Arslan Ekinici, C. Schwieren and M. Strobel, 2010. Women can’t jump? - An experiment on competitive attitudes and stereotype threat. Journal of Economic Behavior \& Organization, 75(3), 395-401.

Halko, M.-L., L. Sääksvuori and K. Timko. 2014. Competitive behavior, stress, and gender. Working paper.

Kandasamy, N., B. Hardy, L. Page, M. Schaffner, J. Graggaber, A.S. Powlson, and J.M. Coates, 2014. Cortisol shifts financial risk preferences. Proceedings of the National Academy of Sciences, 111(9), 3608-3613.

Kavanagh, J., 2005. Stress and performance: A review of the literature and its applicability to the military. Working paper.

Kirschbaum, C. and D.H. Hellhammer, 1989. Salivary cortisol in psychobiological research: An overview. Neuropsychobiology, 22, 150-169.

Kirschbaum, C., K.-M. Pirke and D.H. Hellhammer, 1994. Preliminary evidence for reduced cortisol responsivity to psychological stress in women using oral contraceptive medication. Psychoneuroendocrinology, 20(5), 509-514.

Lighthall, N.R., M. Mather and M.A. Gorlick, 2009. Acute stress increases sex differences in risk seeking in the balloon analogue risk task. PLoS ONE, 4(7), e6002.

Mayr, U., D. Wozniak, C. Davidson, D. Kuhns and B. Harbaugh, 2012. Competitiveness across the life span: The feisty fifties. Psychology and Aging, 27(2), 278-285.

Mehta, P., K.M. Welker, S. Zilioli and J.M. Carré, in press. Testosterone and cortisol jointly modulate risk-taking. Psychoneuroendocrinology.

Mendes, W.B., 2009. Assessing the autonomic nervous system. In Methods in social neuroscience, $118-147$.

Niederle, M. and L. Vesterlund, 2007. Do women shy away from competition? Do men compete too much? Quarterly Journal of Economics, 122, 1067-1101.

Niederle, M. and L. Vesterlund, 2010. Explaining the gender gap in math test scores: The role of competition. Journal of Economic Perspectives, 24, 129-144.

Niederle, M., 2014. Gender. Working paper. 
Oppedal Berge, L.I., K. Bjorvatn, A.J. Garcia Pires and B. Tungodden, forthcoming. Competitive in the lab, successful in the field? Journal of Economic Behavior \& Organization.

Porcelli, A.J. and M.R. Delgado, 2009. Acute stress modulates risk taking in financial decision making. Psychological Science, 20(3), 278-283.

Reuben, E., M. Wiswall and B. Zafar, 2013. Preferences and biases in educational choices and labor market expectations: Shrinking the black box of gender. Working paper.

Schipper, B.C., 2014. Sex hormones and choice under risk. Working paper.

Sutter, M., and D. Glätzle-Rützler, forthcoming Gender differences in the willingness to compete emerge early in life and persist. Management Science.

Taylor, S.E., L.C. Klein, B.P. Lewis, T.L. Gruenewald, R.A. Gurung and J.A. Updegraff, 2000. Biobehavioral responses to stress in females: Tend-and-befriend, not fight-or-flight. Psychological Review, 107, 411-429.

van den Bos, R., M. Harteveld and H. Stoop, 2009. Stress and decision-making in humans: Performance is related to cortisol reactivity, albeit differently in men and women. Psychoneuroendocrinology, 34, 1449-1458.

Vining, R.F., R.A. McGinley, J.J. Maksvytis, and K.Y. Ho, 1983. Salivary cortisol: a better measure of adrenal cortical function than serum cortisol. Annals of Clinical Biochememistry, 20, 329-335.

von Dawans, B., U. Fischbacher, C. Kirschbaum, E. Fehr and M. Heinrichs, 2012. The social dimension of stress reactivity: Acute stress increases prosocial behavior in humans. Psychological Science, 23(6), 651-660.

von Dawans, B., C. Kirschbaum and M. Heinrichs, 2011. The trier social stress test for groups (TSST-G): A new research tool for controlled simultaneous social stress exposure in a group format. Psychoneuroendocrinology, 36, 514-522.

Zhang, J., 2012. Can experimental economics explain competitive behavior outside the lab? Working paper. 


\section{Figures}

Figure 1: Stress levels, Experiment 1

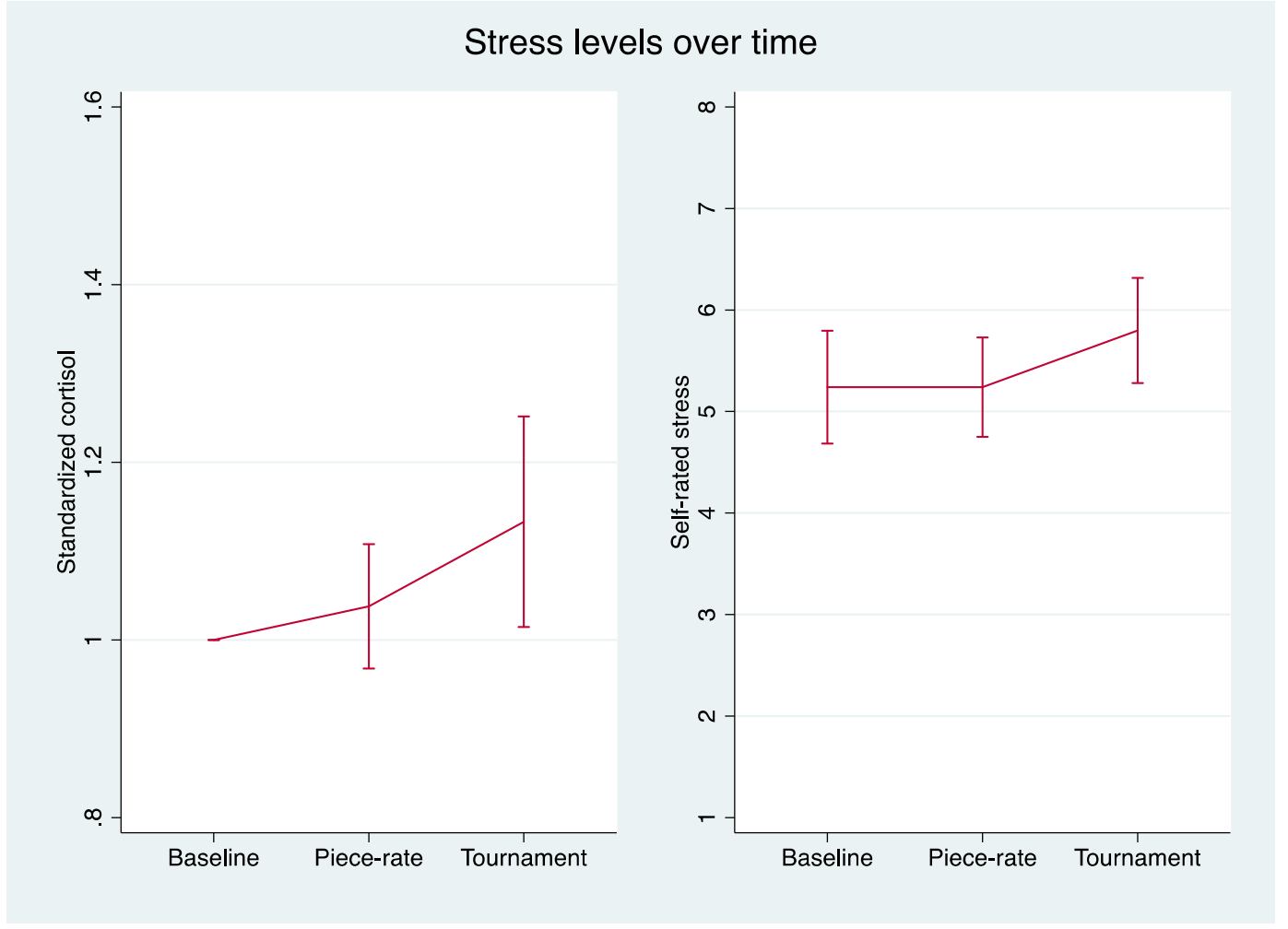

Figure 2: Arousal levels, Experiment 1

Arousal levels over time
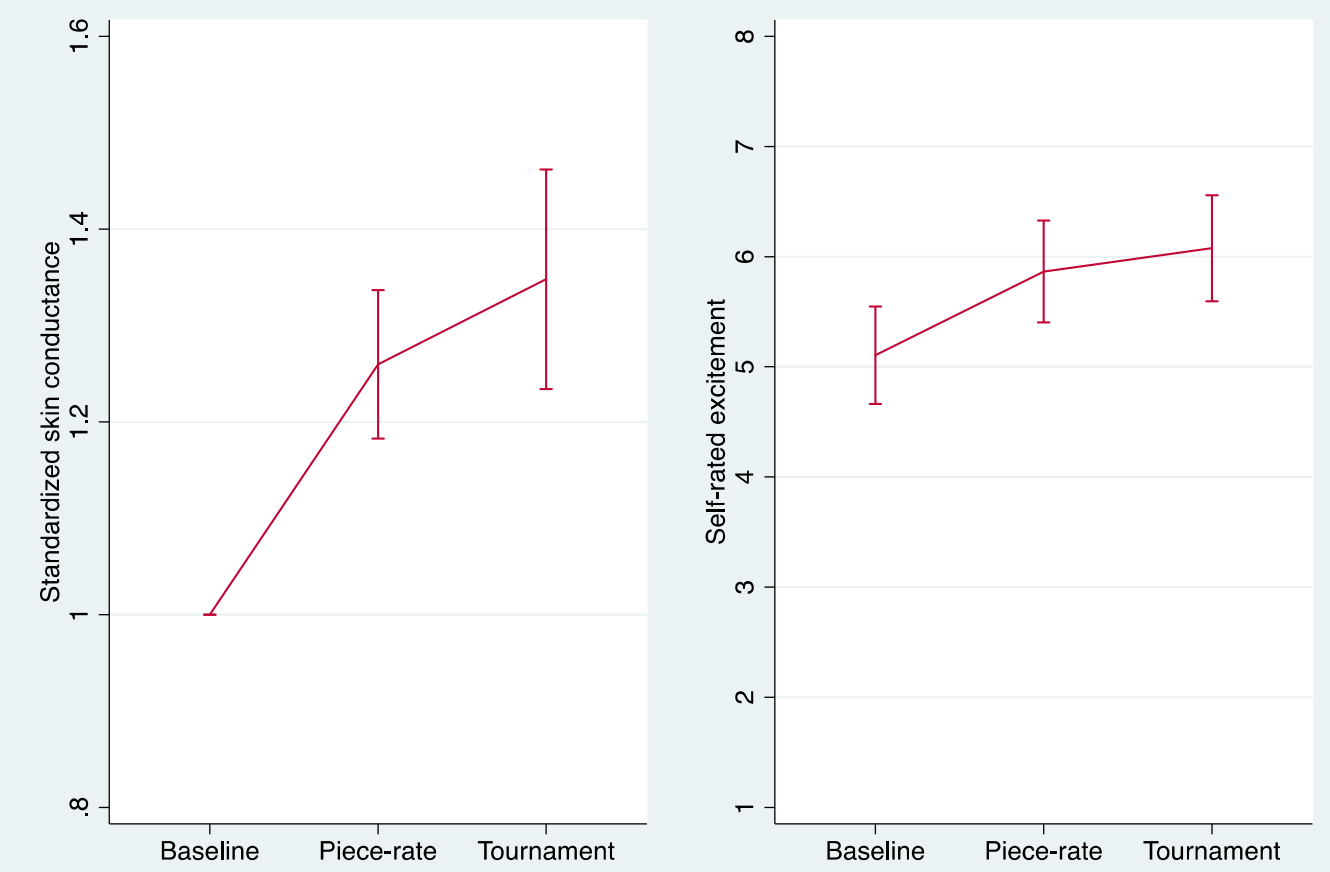
Figure 3: Stress levels by gender, Experiment 1

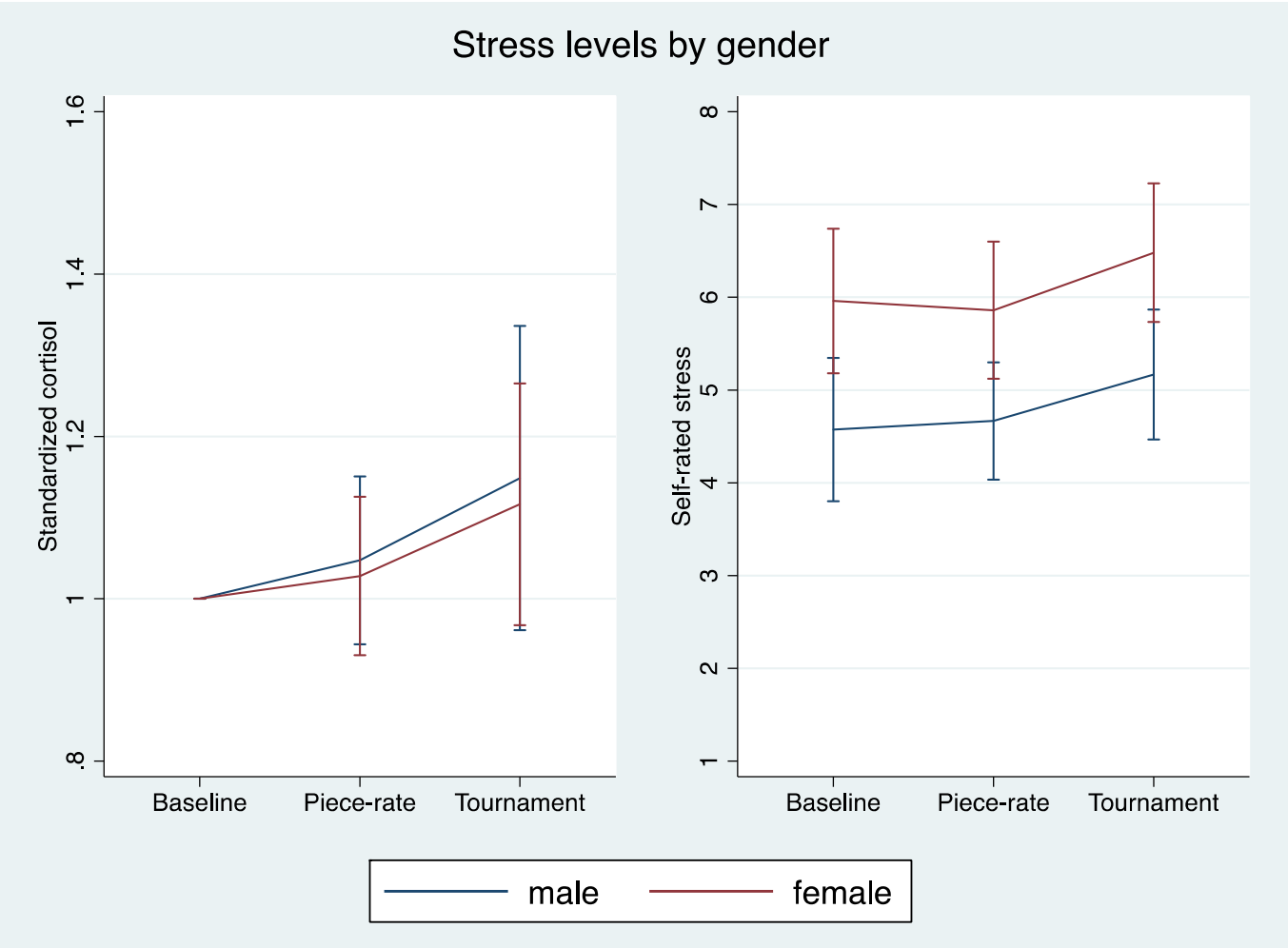

Figure 4: Stress levels by choice, Experiment 1

Stress levels by choice
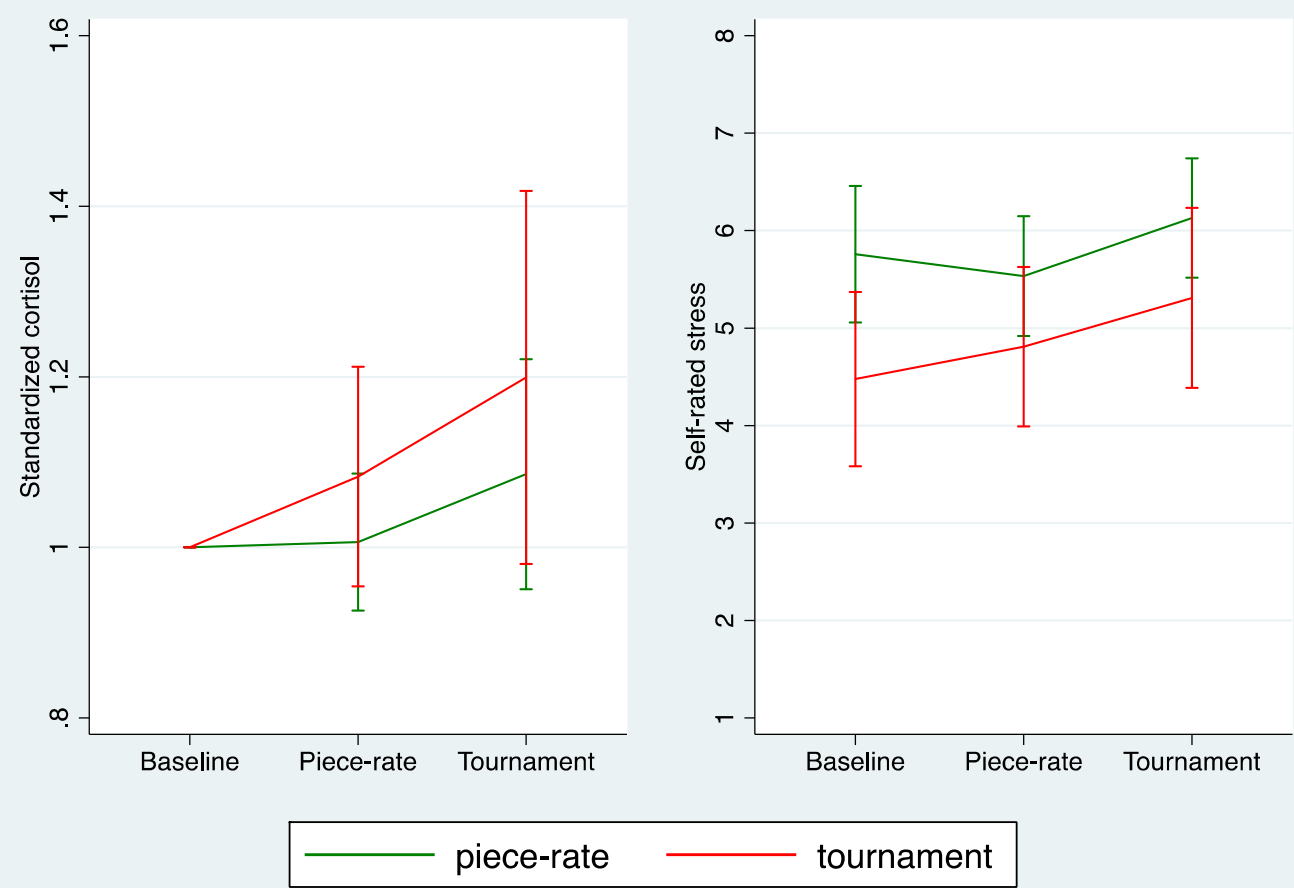
Figure 5: Arousal levels gender, Experiment 1

\section{Arousal levels by gender}

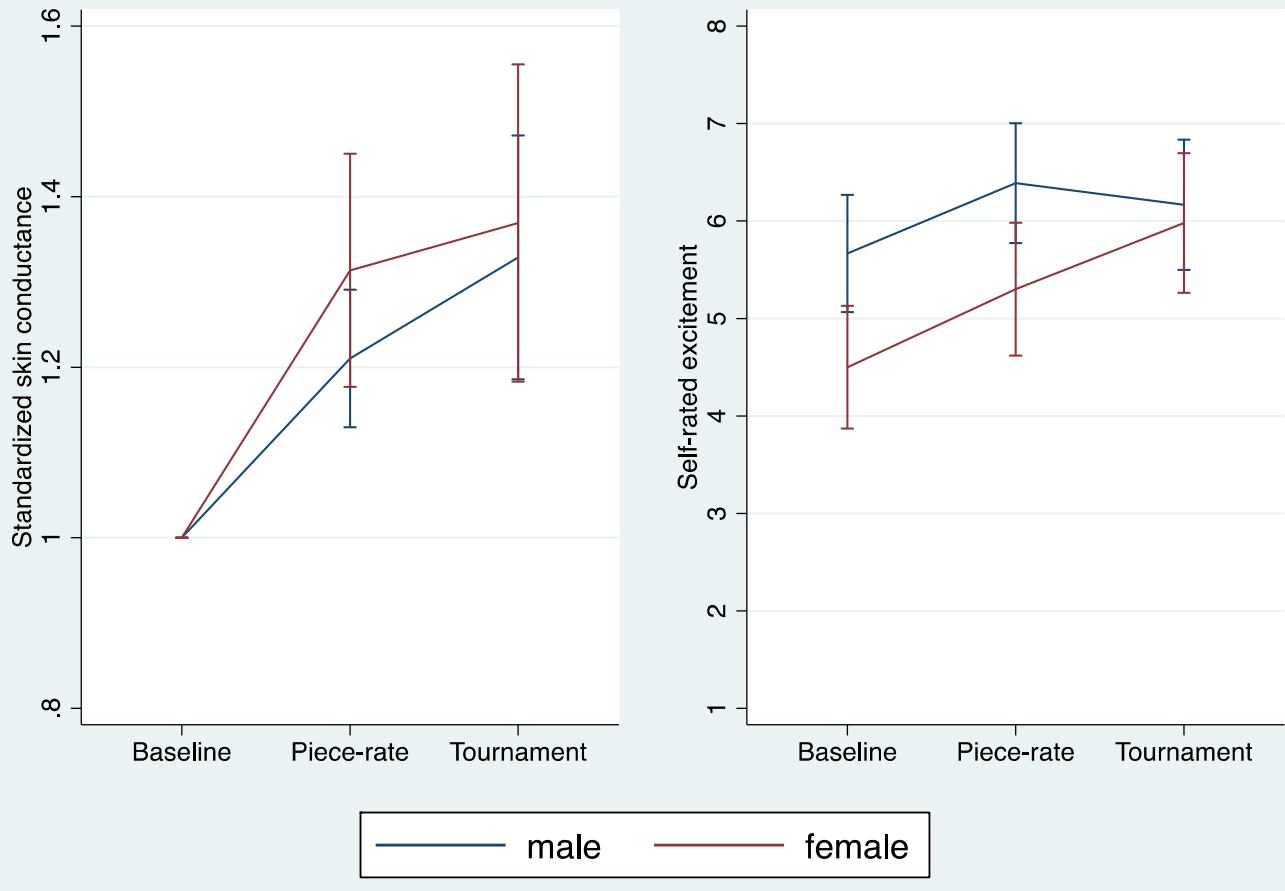

Figure 6: Arousal levels by choice, Experiment 1

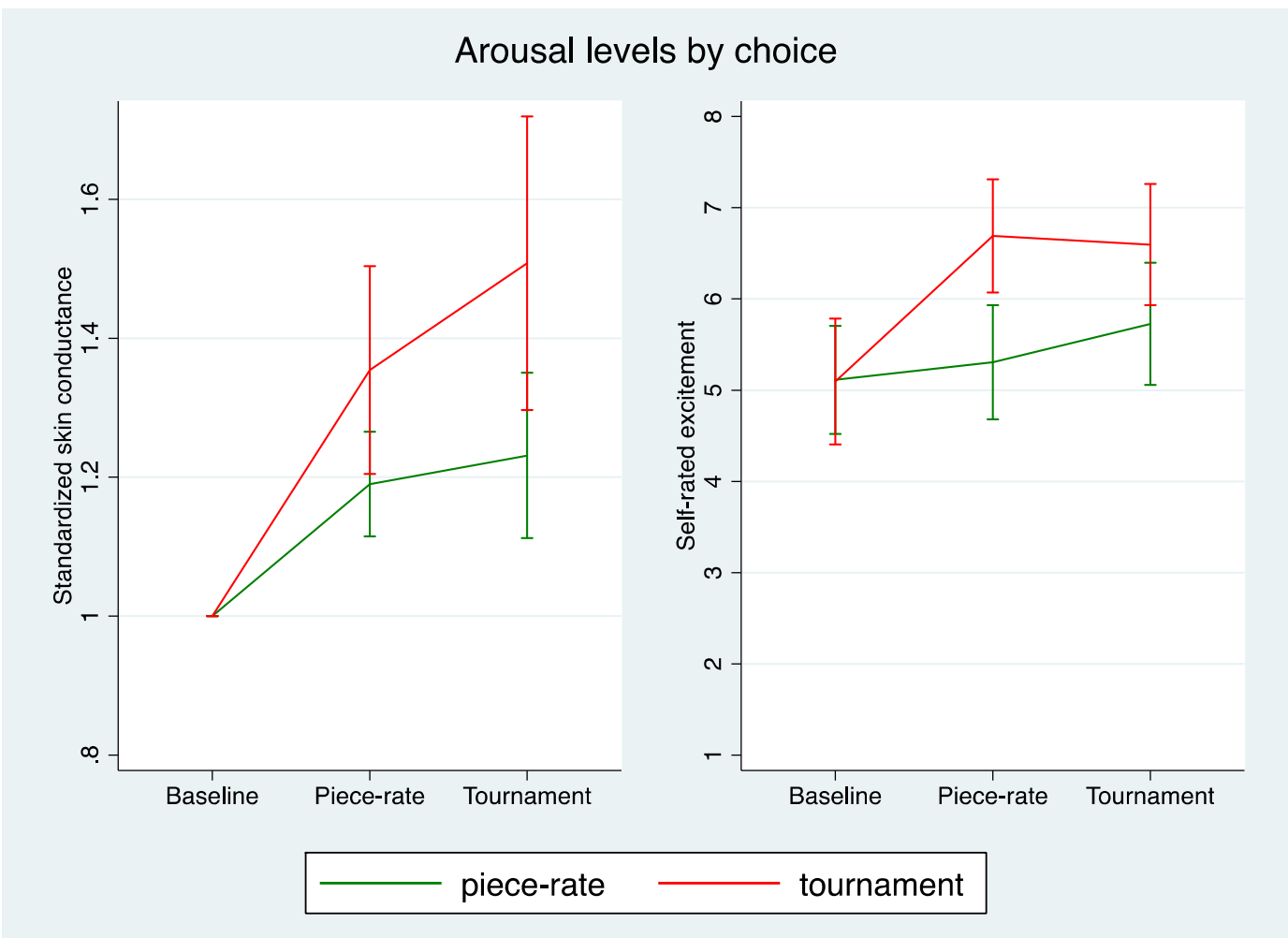


Figure 7: Self-rated stress and excitement, Experiment 2

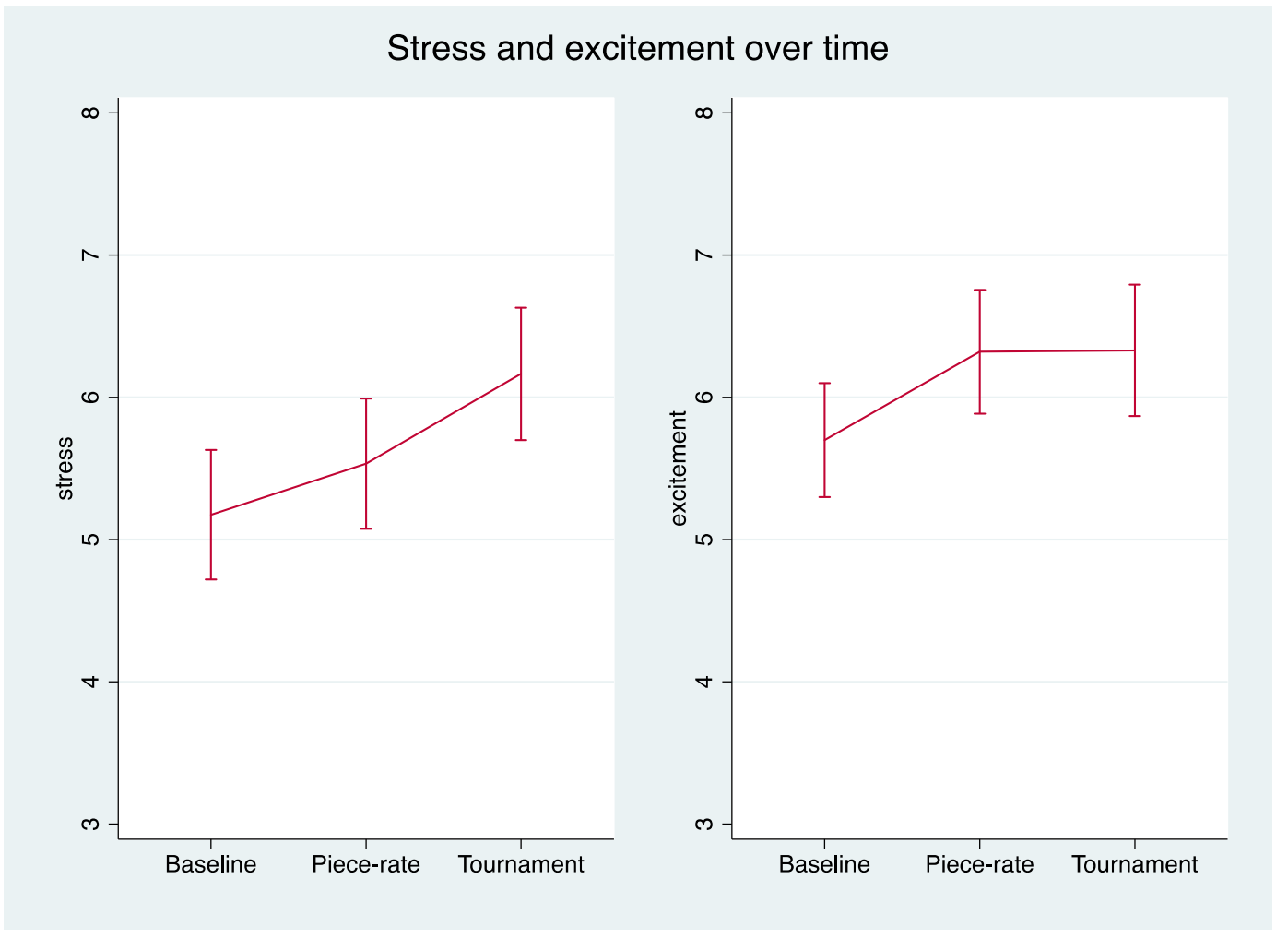

Figure 8: Cortisol levels by stress treatment, Experiment 2

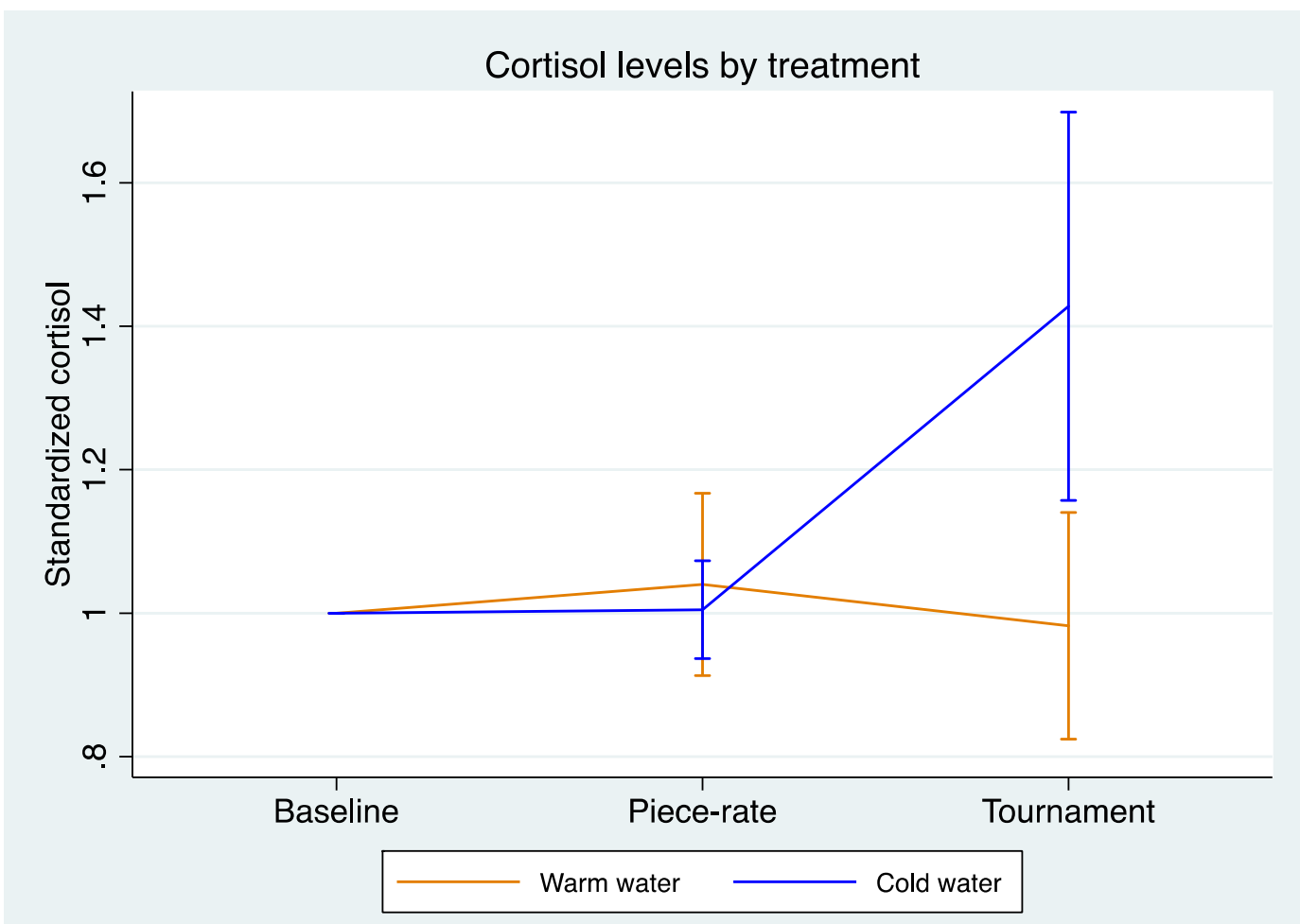




\section{Tables}

Table 1: Summary statistics, Experiment 1

\begin{tabular}{lcccc}
\hline & All & Men & Women & p-value \\
\hline Performance round 1 & 9.90 & 10.31 & 9.46 & 0.24 \\
Performance round 2 & 11.67 & 11.87 & 11.46 & 0.62 \\
Guessed rank round 1 & 2.16 & 2.06 & 2.28 & 0.22 \\
Guessed rank round 2 & 1.94 & 1.96 & 1.92 & 0.81 \\
Self-rated risk attitudes & 5.59 & 6.41 & 4.70 & 0.00 \\
Choosing competition & 0.40 & .52 & .28 & 0.01 \\
\hline Cortisol (baseline, ug/dL) & 0.31 & 0.37 & 0.25 & 0.12 \\
Cortisol (after PR) & 0.30 & 0.37 & 0.23 & 0.17 \\
Cortisol (after competition) & 0.28 & 0.33 & 0.23 & 0.04 \\
Standardized cortisol (after PR) & 1.04 & 1.05 & 1.03 & 0.79 \\
Standardized cortisol (after competition) & 1.13 & 1.15 & 1.12 & 0.79 \\
Standardized skin conductance during PR & 1.26 & 1.21 & 1.31 & 0.18 \\
Standardized skin conductance during competition & 1.35 & 1.33 & 1.37 & 0.73 \\
\hline Self-rated stress (baseline) & 5.24 & 4.57 & 5.96 & 0.01 \\
Self-rated stress (after PR) & 5.24 & 4.67 & 5.86 & 0.02 \\
Self-rated stress (after competition) & 5.8 & 5.17 & 6.48 & 0.01 \\
Self-rated excitement (baseline) & 5.11 & 5.67 & 4.50 & 0.01 \\
Self-rated excitement (after PR) & 5.87 & 6.39 & 5.30 & 0.02 \\
Self-rated excitement (after competition) & 6.08 & 6.17 & 5.98 & 0.70 \\
\hline
\end{tabular}

Note: $p$-values are from t-tests. Standardized cortisol levels means cortisol divided by baseline values. Standardized skin conductance means mean skin conductance during task performance divided by mean baseline levels. Self-rated stress and self-rated excitement are on a scale from 1 to 10. 
Table 2: Willingness to compete and gender (OLS), Experiment 1

\begin{tabular}{lcccc}
\hline & $(1)$ & $(2)$ & $(3)$ & $(4)$ \\
\hline Female & $-0.239^{* *}$ & $-0.210^{* *}$ & $-0.208^{* *}$ & -0.117 \\
& $(0.094)$ & $(0.095)$ & $(0.085)$ & $(0.090)$ \\
Score round 1 & & $0.038^{* *}$ & 0.033 & 0.034 \\
& & $(0.017)$ & $(0.022)$ & $(0.021)$ \\
Score round 2 & -0.010 & -0.030 & -0.028 \\
& & $(0.016)$ & $(0.019)$ & $(0.019)$ \\
Guessed rank round 1 & & -0.103 & $-0.107^{*}$ \\
Guessed rank round 2 & & $(0.062)$ & $(0.062)$ \\
Risk seeking & & $-0.191^{* * *}$ & $-0.173^{* * *}$ \\
& & & $(0.064)$ & $(0.064)$ \\
$\mathrm{R}^{2}$ & & & $0.051^{* * *}$ \\
\hline
\end{tabular}

Note: Dependent variable: dummy indicating choice of competition in round 3. Robust standard errors in parentheses; ${ }^{* * *} p<0.01,{ }^{* *} p<0.05,{ }^{*} p<0.1$. 
Table 3: Willingness to compete and stress (OLS), Experiment 1
(1)
(2)
(3)
(4)
(5)
(6)

\begin{tabular}{|c|c|c|c|c|c|c|}
\hline Female & $\begin{array}{c}-0.253^{* * *} \\
(0.096)\end{array}$ & $\begin{array}{c}-0.251^{* * *} \\
(0.096)\end{array}$ & $\begin{array}{c}-0.244^{* *} \\
(0.097)\end{array}$ & $\begin{array}{c}-0.250^{* *} \\
(0.096)\end{array}$ & $\begin{array}{c}-0.256^{* *} \\
(0.098)\end{array}$ & $\begin{array}{c}-0.248^{* *} \\
(0.098)\end{array}$ \\
\hline Standardized cortisol after PR & & $\begin{array}{c}0.131 \\
(0.138)\end{array}$ & & & & $\begin{array}{c}0.078 \\
(0.232)\end{array}$ \\
\hline Standardized stress after PR & & & $\begin{array}{c}0.038 \\
(0.051)\end{array}$ & & & $\begin{array}{l}0.071^{*} \\
(0.037)\end{array}$ \\
\hline Standardized cortisol after comp. & & & & $\begin{array}{c}0.072 \\
(0.087)\end{array}$ & & $\begin{array}{c}0.022 \\
(0.146)\end{array}$ \\
\hline Standardized stress after comp. & & & & & $\begin{array}{l}-0.012 \\
(0.047)\end{array}$ & $\begin{array}{l}-0.052 \\
(0.039)\end{array}$ \\
\hline $\mathrm{N}$ & 101 & 101 & 101 & 101 & 101 & 101 \\
\hline $\mathrm{R}^{2}$ & 0.066 & 0.075 & 0.071 & 0.073 & 0.066 & 0.086 \\
\hline
\end{tabular}

Note: Dependent variable: dummy indicating choice of competition in round 3. Robust standard errors in parentheses; $* * * p<0.01,{ }^{* *} p<0.05, * p<0.1$. 
Table 4: Willingness to compete and arousal (OLS), Experiment 1
(1)
(2)
(3)
(4)
(5)
(6)

Female

$-0.230^{* *}$

$-0.264^{* * *}$

$-0.242^{* *}$

$-0.239 * *$

$-0.260 * * *$

$-0.258 * * *$

$(0.102)$

$(0.100)$

(0.097)

(0.099)

(0.098)

(0.097)

Standardized skin cond. during PR

$0.359 * * *$

0.098

(0.119)

Standardized excitement after PR

$$
0.150 * * *
$$

(0.047)

Standardized skin cond. during comp.

$0.239 * * *$

(0.087)

Standardized excitement after comp

$(0.030) \quad(0.086)$

\begin{tabular}{lccccccc}
\hline $\mathrm{N}$ & 90 & 90 & 90 & 90 & 90 & 90 \\
$\mathrm{R}^{2}$ & 0.054 & 0.125 & 0.144 & 0.122 & 0.124 & 0.181
\end{tabular}

Note: Dependent variable: dummy indicating choice of competition in round 3. Robust standard errors in parentheses; ${ }^{* * *} p<0.01,{ }^{* *} p<0.05,{ }^{*} p<0.1$. The number of observations is slightly smaller than in Table 3 because for some participants, skin conductance was not measured at the relevant moments due to equipment malfunctioning. 
Table 5: Willingness to compete and stress: gender differences (OLS), Experiment 1

\begin{tabular}{|c|c|c|c|c|c|c|}
\hline & (1) & (2) & (3) & (4) & (5) & (6) \\
\hline & All & All & Men & Women & $\begin{array}{c}\text { cortisol> } \\
\text { mean }\end{array}$ & $\begin{array}{c}\text { cortisol< } \\
\text { mean }\end{array}$ \\
\hline \multirow[t]{2}{*}{ Female } & $-0.716^{* *}$ & $-0.624 * * *$ & & & -0.076 & $-0.374 * * *$ \\
\hline & $(0.281)$ & $(0.202)$ & & & $(0.158)$ & $(0.118)$ \\
\hline \multirow[t]{2}{*}{ Stdandardized cortisol after PR } & -0.067 & & & & & \\
\hline & $(0.196)$ & & & & & \\
\hline \multirow[t]{2}{*}{ Female*Std. cortisol after PR } & $0.446^{*}$ & & & & & \\
\hline & $(0.257)$ & & & & & \\
\hline \multirow[t]{2}{*}{ Standardized cortisol after comp. } & & -0.047 & -0.047 & $0.284^{* *}$ & & \\
\hline & & $(0.110)$ & $(0.110)$ & $(0.113)$ & & \\
\hline \multirow[t]{2}{*}{ Female*Std. cortisol after comp. } & & $0.331^{* *}$ & & & & \\
\hline & & $(0.158)$ & & & & \\
\hline $\mathrm{N}$ & 101 & 101 & 52 & 49 & 41 & 60 \\
\hline r2 & 0.100 & 0.110 & 0.004 & 0.104 & 0.006 & 0.145 \\
\hline
\end{tabular}

Note: Dependent variable: dummy indicating choice of competition in round 3. Robust standard errors in parentheses; ${ }^{* *} p<0.01,{ }^{* *} p<0.05,{ }^{*} p<0.1$. 
Table 6: Summary statistics, Experiment 2

\begin{tabular}{|c|c|c|c|c|c|c|c|}
\hline & All & Control & Treatment & $\mathrm{p}$ & Men & Women & $\mathrm{p}$ \\
\hline Performance round 1 & 10.19 & 10.24 & 10.15 & 0.91 & 10.33 & 10.09 & 0.76 \\
\hline Performance round 2 & 11.38 & 11.34 & 11.42 & 0.93 & 11.89 & 10.96 & 0.31 \\
\hline Guessed rank round 1 & 2.27 & 2.14 & 2.40 & 0.13 & 2.28 & 2.26 & 0.91 \\
\hline Guessed rank round 2 & 1.98 & 1.90 & 2.06 & 0.37 & 2.00 & 1.96 & 0.84 \\
\hline Risk attitudes & 5.85 & 5.64 & 6.06 & 0.39 & 6.26 & 5.53 & 0.13 \\
\hline Choosing competition & 0.43 & 0.40 & 0.45 & 0.59 & 0.59 & 0.30 & 0.00 \\
\hline Cortisol (baseline) & 0.28 & 0.28 & 0.28 & 0.98 & 0.28 & 0.28 & 0.91 \\
\hline Cortisol (after PR) & 0.27 & 0.27 & 0.26 & 0.86 & 0.3 & 0.25 & 0.16 \\
\hline Cortisol (after treatment) & 0.30 & 0.25 & 0.35 & 0.02 & 0.35 & 0.26 & 0.04 \\
\hline Standardized cortisol (after PR) & 1.02 & 1.04 & 1.00 & 0.62 & 1.11 & 0.95 & 0.03 \\
\hline Standardized cortisol (after treatment) & 1.21 & 0.98 & 1.43 & 0.01 & 1.38 & 1.07 & 0.06 \\
\hline Self-rated stress (baseline) & 5.17 & 5.14 & 5.21 & 0.88 & 4.98 & 5.33 & 0.45 \\
\hline Self-rated stress (after PR) & 5.53 & 5.22 & 5.83 & 0.19 & 5.39 & 5.65 & 0.58 \\
\hline Self-rated stress (after competition) & 6.17 & 6.00 & 6.32 & 0.50 & 5.80 & 6.46 & 0.17 \\
\hline Self-rated excitement (baseline) & 5.70 & 5.58 & 5.81 & 0.57 & 5.72 & 5.68 & 0.94 \\
\hline Self-rated excitement (after PR) & 6.32 & 6.16 & 6.47 & 0.48 & 6.35 & 6.30 & 0.91 \\
\hline Self-rated excitement (after competition) & 6.33 & 6.58 & 6.09 & 0.30 & 6.48 & 6.21 & 0.57 \\
\hline
\end{tabular}

Note: p-values are from t-tests. Standardized cortisol levels means cortisol divided by baseline values. Self-rated stress and self-rated excitement are on a scale from 1 to 10. 
Table 7: Causal effect of stress on willingness to compete (OLS), Experiment 2
(1)
(2)
(3)
(4)
(5)
(6)

\begin{tabular}{lcccccc}
\hline Female & $-0.289^{* * *}$ & $-0.255^{* * *}$ & $-0.302^{* * *}$ & $-0.270^{* * *}$ & $-0.288^{* * *}$ & $-0.272^{* * *}$ \\
& $(0.095)$ & $(0.091)$ & $(0.081)$ & $(0.086)$ & $(0.096)$ & $(0.086)$ \\
Cold Water & & & & & 0.049 & 0.075 \\
& & & & & $(0.094)$ & $(0.080)$ \\
Score round 1 & & & & & $0.043^{* *}$ \\
& & 0.008 & $0.036^{*}$ & $0.043^{* *}$ & & $(0.019)$ \\
Score round 2 & & $(0.020)$ & $(0.018)$ & $(0.019)$ & & -0.017 \\
& & $0.035^{* *}$ & -0.013 & -0.016 & & $(0.019)$ \\
Guessed rank round 1 & & $(0.017)$ & $(0.018)$ & $(0.019)$ & & 0.007 \\
Guessed rank round 2 & & & 0.014 & 0.013 & & $(0.052)$ \\
& & & $(0.054)$ & $(0.051)$ & & $-0.252^{* * *}$ \\
Risk seeking & & & $-0.275^{* * *}$ & $-0.248^{* * *}$ & & $(0.055)$ \\
& & & $(0.055)$ & $(0.056)$ & & $0.041^{* *}$ \\
r2 & & & & $0.043^{* *}$ & & $(0.017)$ \\
\hline
\end{tabular}

Note: Dependent variable: dummy indicating choice of competition in round 3. Cold Water is a dummy indicating a participant has been randomly assigned to the treatment group. Robust standard errors in parentheses; ${ }^{* * *} p<0.01,{ }^{* *} p<0.05,{ }^{*} p<0.1$. 
Table 8: Causal effect of stress on willingness to compete: gender differences (OLS),

\section{Experiment 2}

\begin{tabular}{|c|c|c|c|c|c|c|c|}
\hline & (1) & (2) & (3) & (4) & (5) & (6) & (7) \\
\hline & All & $\begin{array}{l}\text { Treatment } \\
\text { effective }\end{array}$ & All & Men & Women & $\begin{array}{c}\text { Treatment } \\
\text { group }\end{array}$ & $\begin{array}{l}\text { Control } \\
\text { group }\end{array}$ \\
\hline \multirow[t]{2}{*}{ Female } & $-0.422 * * *$ & $-0.422 * * *$ & $-0.587 * * *$ & & & -0.162 & $-0.422 * * *$ \\
\hline & $(0.131)$ & $(0.132)$ & $(0.165)$ & & & $(0.139)$ & $(0.131)$ \\
\hline \multirow[t]{2}{*}{ Cold Water } & -0.095 & -0.208 & & -0.095 & 0.165 & & \\
\hline & $(0.147)$ & $(0.171)$ & & $(0.148)$ & $(0.121)$ & & \\
\hline \multirow[t]{2}{*}{ Female*Cold Water } & 0.260 & $0.444 * *$ & & & & & \\
\hline & $(0.191)$ & $(0.221)$ & & & & & \\
\hline \multirow[t]{2}{*}{ Standardized cortisol $\left(3^{\text {rd }}\right)$} & & & -0.071 & & & & \\
\hline & & & $(0.054)$ & & & & \\
\hline \multirow[t]{2}{*}{ Female* Std. cortisol $\left(3^{\text {rd }}\right)$} & & & $0.258 * *$ & & & & \\
\hline & & & $(0.121)$ & & & & \\
\hline $\mathrm{N}$ & 103 & 84 & 103 & 46 & 57 & 53 & 50 \\
\hline $\mathrm{R}^{2}$ & 0.104 & 0.109 & 0.121 & 0.009 & 0.033 & 0.026 & 0.183 \\
\hline
\end{tabular}

Note: Dependent variable: dummy indicating choice of competition in round 3. Cold Water is a dummy indicating a participant has been randomly assigned to the treatment group. Robust standard errors in parentheses; ${ }^{* * *} p<0.01,{ }^{* *} p<0.05,{ }^{*} p<0.1$. 
Table 9: Cortisol and performance

(1)

(2)

(3)

(4)

(5)

(6)

(7)

Experiment 1:

Experiment 2:

Dependent variable

Score

Score

Score

Score

round 2

round 2

round 2

round 2

round 3

round 3

round 3

Std. cortisol after PR

0.891

$-0.222$

$(0.841)$

(0.892)

Std. cortisol after competition

0.388

$-0.132$

(0.585)

Std. skin cond during PR

$$
-0.207
$$

(0.691)

Std. skin cond during compet.

0.109

(0.561)

Cold Water

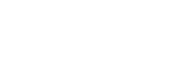

(0.109)

(0.109)

$\begin{array}{lll}(0.086) \quad(0.084) & (0.087)\end{array}$

Competes

$1.303^{* *} \quad 1.311^{* *} \quad 1.311^{* *}$

$\begin{array}{lll}(0.565) & (0.573) \quad(0.568)\end{array}$

\begin{tabular}{lcccccccc}
\hline $\mathrm{N}$ & 101 & 101 & 90 & 90 & 103 & 103 & 103 \\
$\mathrm{R}^{2}$ & 0.580 & 0.577 & 0.504 & 0.504 & 0.722 & 0.723 & 0.723
\end{tabular}

Note: Cold Water is a dummy indicating a participant has been randomly assigned to the treatment group. Robust standard errors in parentheses; ${ }^{* * *} p<0.01,{ }^{* *} p<0.05,{ }^{*} p<0.1$. 